\title{
Modelling and Optimization of Process Parameters for Strawberry Osmotic Dehydration Using Central Composite Rotatable Design
}

\author{
Bei Liu and Bangzhu Peng \\ Key Laboratory of Environment Correlative Dietology, Ministry of Education, College of Food Science \& Technology, \\ Huazhong Agricultural University, Wuhan, Hubei 430070, China
}

Correspondence should be addressed to Bangzhu Peng; pengbangzhu@163.com

Received 30 March 2017; Revised 16 June 2017; Accepted 5 July 2017; Published 1 August 2017

Academic Editor: Susana Fiszman

Copyright (C) 2017 Bei Liu and Bangzhu Peng. This is an open access article distributed under the Creative Commons Attribution License, which permits unrestricted use, distribution, and reproduction in any medium, provided the original work is properly cited.

Osmotic dehydration conditions for strawberry were optimized using central composite rotatable design. The optimal conditions included osmotic dehydration temperature of $59.5^{\circ} \mathrm{C}$, osmotic dehydration time of $245.6 \mathrm{~min}$, and sorbitol concentration of $66.8 \%$. Water loss (WL) exhibited a response value of $52.5 \%$ and was mainly influenced by sorbitol concentration $(p \leq 0.01)$, followed by osmotic dehydration temperature $(p \leq 0.01)$ and time $(p \leq 0.01)$. The optimal condition was validated and found to be fitted well with the experimental data. The osmotic dehydration of strawberry was significantly influenced by osmotic dehydration temperature and time and sorbitol concentration. Based on the parameters of ANOVA, the predicted model for WL rate established by response surface quadratic regression provided an adequate mathematical description of the osmotic dehydration of strawberry.

\section{Introduction}

Strawberry is a highly perishable fruit with intense metabolic activity after harvest. Its consumption was restricted to a short period of time because of the presence of enzymes and microorganisms. Thus, new preservation techniques are needed.

Osmotic dehydration is a potential preservation technique for producing high-quality products and is widely used for partial removal of water from food materials by immersion in an osmotic solution. Osmotic dehydration exhibits many benefits in the food industry; this process features energy efficiency, reduced packaging and distribution cost, and lack of chemical treatments and generates high-quality and stable products during storage [1-3]. This process is usually followed by other drying methods, such as air drying or freeze drying, to obtain products with improved quality [3-6].

When the strawberry samples are soaked in the concentrated solutions, three simultaneous mass transfer phenomena occur; these phenomena include flow of water from the product to the solution, transfer of solute into the product, and leaching of the components of the product. Mass transfer continues from the surface to the center of the strawberry with increasing dehydration time. Finally, cells in the center of the strawberry lose water to reach the equilibrium mass transfer flux. The pressure difference between the strawberry and solution gives rise to simultaneous counter-current water diffusion from the strawberry into the solution and solute diffusion into the strawberry [7, 8]. Moisture is mainly removed by capillary flow and diffusion; meanwhile, leaching and solute uptake occur through diffusion $[3,9]$.

Moraga et al. [10] applied osmotic dehydration as initial pretreatment before convective drying process for strawberries. Osorio et al. [11] reported that the osmotic dehydration of tamarillo and Andes berry decreased the water activity and enhanced the elution of flavor constituents and anthocyanin into the osmotic solution. Azoubell and Francinaide [12] investigated the effect of osmotic dehydration on mango fruit by varying osmotic temperature $\left(30-50^{\circ} \mathrm{C}\right)$, solution concentration (40-60\%), and immersion time (60-150 $\mathrm{min}$ ); the maximum water removal was obtained under the optimal 
TABLE 1: Independent variables and their levels used in the central composite rotatable design for strawberry osmotic dehydration.

\begin{tabular}{lccc}
\hline Coded levels & & Natural levels & \\
& Temperature $\left({ }^{\circ} \mathrm{C}\right)$ & Sorbitol concentration (\%) & Time (min) \\
\hline-1.68 & 46.59 & 33.18 & 115.91 \\
-1 & 50 & 45 & 150 \\
0 & 55 & 50 & 200 \\
1 & 60 & 65 & 250 \\
1.68 & 63.41 & 66.82 & 284.09 \\
\hline
\end{tabular}

condition comprising sucrose solution of $44 \%$, processing time of $80 \mathrm{~min}$, and temperature of $38^{\circ} \mathrm{C}$. Therefore, the rate of mass transfer during osmotic dehydration is influenced by many factors, such as type and concentration of osmotic agents, temperature, agitation, solution to sample ratio, thickness of food material, and pretreatment [13-18].

Response surface methodology (RSM) is an effective mathematical tool for optimizing independent factors that influence responses in a given set of experiments [19]. RSM not only defines the effect of independent variables but also their interaction effects [20]. Meanwhile, osmotic dehydration parameters for strawberry must be optimized before industrial application. Therefore, the present study aims to determine the optimal osmotic dehydration conditions of independent variables (osmotic temperature, time, and solute concentration) for strawberry and validate the optimized conditions based on water loss rate by using RSM coupled with central composite rotatable design. In addition, the effects of different solute concentrations on strawberry water loss (WL) and solid gain (SG) rates were analyzed.

\section{Materials and Methods}

2.1. Sample Preparation. Strawberries of Hongyan cultivar were obtained directly from a producer from Fu jiabian town (Nanjing, China). The average values of single weight, $\mathrm{pH}$, and total soluble solid contents in the strawberries were $16.2 \mathrm{~g}$, 4.1, and 5.1 brix, respectively. The fruits were washed and cut into cubes $(1 \times 1 \times 1 \mathrm{~cm})$ to prepare samples.

2.2. Osmotic Dehydration Treatment. D-Sorbitol ( $\geq 98 \%$, Sigma-Aldrich Corporation) was chosen as the osmotic solute. The strawberry cube samples were subjected to osmotic dehydration under different temperatures, times, and sorbitol concentrations based on the experimental design. The ratio of the strawberry cubes to the osmotic solution was $1: 8$ by weight. The vessel was installed in water bath with frail agitation of $100 \mathrm{rpm}$ and was covered with a wrap to prevent evaporation. After the osmotic treatment, the samples were removed from the osmotic solution, washed with distilled water, and blotted gently with a tissue paper to remove adhering water for the next analysis [21, 22]

2.3. Optimization of Osmotic Dehydration Using Central Composite Rotatable Design. A central composite rotatable design was used to optimize the conditions for osmotic dehydration of strawberry cubes. Osmotic temperature, time, and sorbitol concentration were taken as independent variables to optimize WL rate and determine the efficiency of osmotic dehydration. The experimental data were fitted using multiple linear regression in $[23,24]$

$$
Y=b_{0}+\sum_{i=1}^{3} b_{i} X_{i}+\sum_{i=1}^{3} b_{i i} X_{i}^{2}+\sum_{i=1}^{3} \sum_{j=(i+1)}^{3} b_{i j} X_{i} X_{j},
$$

where $Y$ is the WL rate, $i$ and $j$ are the linear and quadratic coefficients, respectively, $X_{i}$ and $X_{j}$ represent three independent variables, and $b_{0}, b_{i}, b_{i i}$, and $b_{i j}$ are the regression coefficients.

Table 1 shows the three independent variables and level coded values determined by Design Expert software, 7.0 (StatEase, Inc., MN, USA).

2.4. Mass Transfer Determination. The samples were prepared following the central composite rotatable design; then the process kinetic variables of WL and SG rates of the samples were calculated as described by Singh et al. [25] and Falade et al. [26] by using

$$
\begin{aligned}
\mathrm{WL} \% & =\frac{\left(M_{0}-m_{0}\right)-\left(M_{t}-m_{t}\right)}{M_{0}} \times 100 \% \\
\mathrm{SG} \% & =\frac{m_{t}-m_{0}}{M_{0}} \times 100 \%,
\end{aligned}
$$

where $M_{0}$ and $m_{0}$ are the initial mass weights of the strawberry samples and the dry solid mass in the samples (g), respectively; $M_{t}$ and $m_{t}$ are the mass weights of the samples and the dry solids (g) in the samples after the osmotic dehydration time $t$.

\section{Results and Discussion}

3.1. Fitting the Model. In this study, central composite rotatable design coupled with RSM was used to optimize osmotic dehydration for strawberry cubes. The response of WL rate was selected on the basis that the response directly influenced the drying efficiency of the product. The three independent variables, namely, osmotic temperature, time, and sorbitol concentration (coded $A, B$, and $C$, resp.) were used to optimize the response of WL rate coded $Y$. The experimental design and obtained values are shown in Table 2. Regression analysis of the response was conducted by fitting a suitable quadratic model in the case of the response variable to assess how well the model represented the data. The results of the analysis of variance (ANOVA) for the WL rate regression 
TABLE 2: Experimental design and experimentally obtained values of WL rate for strawberry osmotic dehydration.

\begin{tabular}{lcccc}
\hline Number & $A$ - Temperature $\left({ }^{\circ} \mathrm{C}\right)$ & $B$-Time $(\mathrm{min})$ & $C$-Sorbitol concentration $(\%)$ & $Y$-Water loss rate $(\%)^{*}$ \\
\hline 1 & 47 & 200 & 50 & 43.9 \\
2 & 60 & 250 & 60.6 & 41.3 \\
3 & 60 & 150 & 60 & 47.0 \\
4 & 60 & 150 & 50 & 46.8 \\
5 & 55 & 200 & 40 & 44.8 \\
6 & 50 & 250 & 50 & 46.8 \\
7 & 55 & 200 & 50 & 49.0 \\
8 & 55 & 284 & 67 & 50.6 \\
9 & 55 & 200 & 50 & 46.1 \\
10 & 63 & 200 & 33 & 40.8 \\
11 & 55 & 200 & 60 & 42.2 \\
12 & 50 & 150 & 40 & 38.1 \\
13 & 50 & 150 & 50 & 46.8 \\
14 & 55 & 200 & 50 & 46.8 \\
15 & 55 & 200 & 50 & 38.6 \\
16 & 55 & 116 & 50 & 46.8 \\
17 & 55 & 200 & 60 & 49.3 \\
18 & 50 & 250 & 50 & 46.8 \\
20 & 55 & 200 & 40 & 4.2 \\
\hline
\end{tabular}

${ }^{*}$ Each combination was carried out in triplicate and water loss rate was expressed by average value for eliminating experimental errors.

TABLE 3: ANOVA of WL rate regression model for strawberry osmotic dehydration.

\begin{tabular}{|c|c|c|c|c|c|}
\hline Source & Sum of squares & Degree of freedom & Mean square & $F$ value & $p$ value $^{*}$ \\
\hline Model & 241.90 & 9 & 26.88 & 109.55 & $<0.0001$ \\
\hline$A$ & 94.41 & 1 & 94.41 & 384.81 & $<0.0001$ \\
\hline$B$ & 13.55 & 1 & 13.55 & 55.23 & $<0.0001$ \\
\hline C & 108.93 & 1 & 108.93 & 443.97 & $<0.0001$ \\
\hline$A B$ & 0.75 & 1 & 0.75 & 3.06 & 0.1109 \\
\hline$A C$ & $3.613 E-003$ & 1 & $3.613 E-003$ & 0.015 & 0.9058 \\
\hline$B C$ & 4.85 & 1 & 4.85 & 19.77 & 0.0012 \\
\hline$A^{2}$ & 1.81 & 1 & 1.81 & 7.50 & 0.0209 \\
\hline$B^{2}$ & 5.16 & 1 & 5.16 & 61.77 & $<0.0001$ \\
\hline$C^{2}$ & 1.81 & 1 & 1.84 & 7.50 & 0.0209 \\
\hline Residual & 2.45 & 10 & 0.25 & & \\
\hline Lack of fit & 2.45 & 5 & 0.49 & & \\
\hline Pure error & 0.000 & 5 & 0.000 & & \\
\hline Total & 244.36 & 19 & & & \\
\hline
\end{tabular}

A: temperature $\left({ }^{\circ} \mathrm{C}\right) ; B$ : time (min); C: sorbitol concentration $(\%) ;{ }^{*} p$ values less than 0.05 indicate model terms are significant, and values greater than 0.1 indicate the model terms are not significant.

model are shown in Table 3. According to the estimated regression coefficients of the quadratic polynomial model in Table 3, nonsignificant factors were removed. The regression model was obtained to express the relationship between the investigated variables and WL rate of the samples:

$$
\begin{aligned}
Y= & 46.75+1.00 \times A+2.82 \times B+2.63 \times C-0.78 \times B \\
& \times A+0.31 \times C \times A+0.021 \times B \times C-0.60 \times A^{2} \\
& -1.03 \times B^{2}-0.36 \times C^{2} .
\end{aligned}
$$

The $F$ value implied that the model was very significant $(p<$ 0.01 ) and accurately predicted the WL rate of the samples.

As shown in Table 3, osmotic time, sorbitol concentration, and temperature significantly affected the strawberry osmotic dehydration rate $(p<0.01)$; the model of Prob $>$ $F$ and less than 0.01 indicated that the regression equation exhibited high significance and reliability. Meanwhile, the coefficient $R^{2}$ of the regression model was found to be 0.990 , greater than $90 \%$, indicating the significant relationship between the independent variable and the response value. 


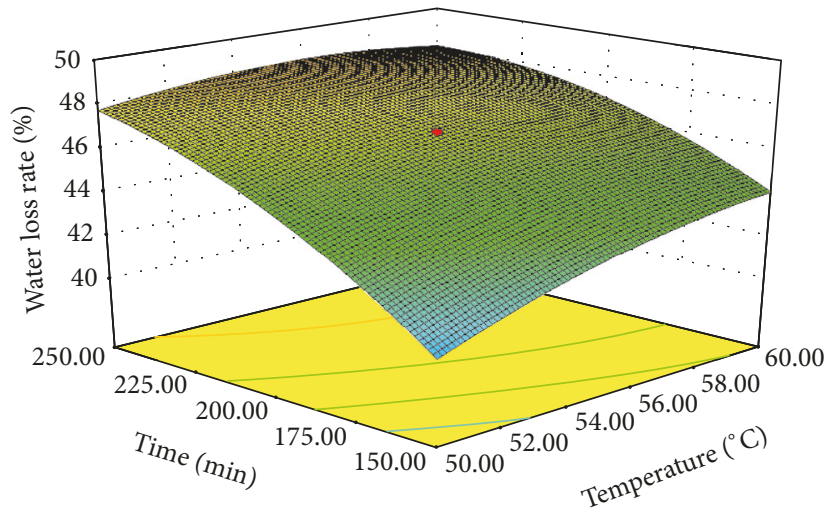

(a)

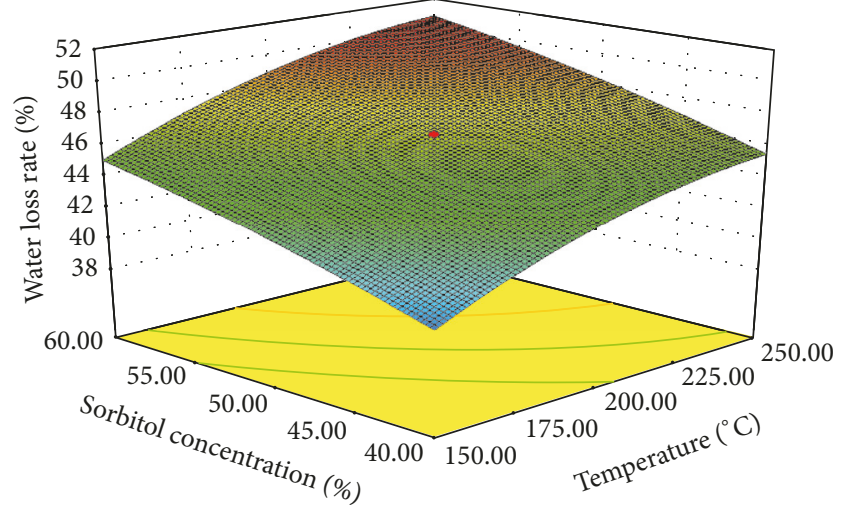

(b)

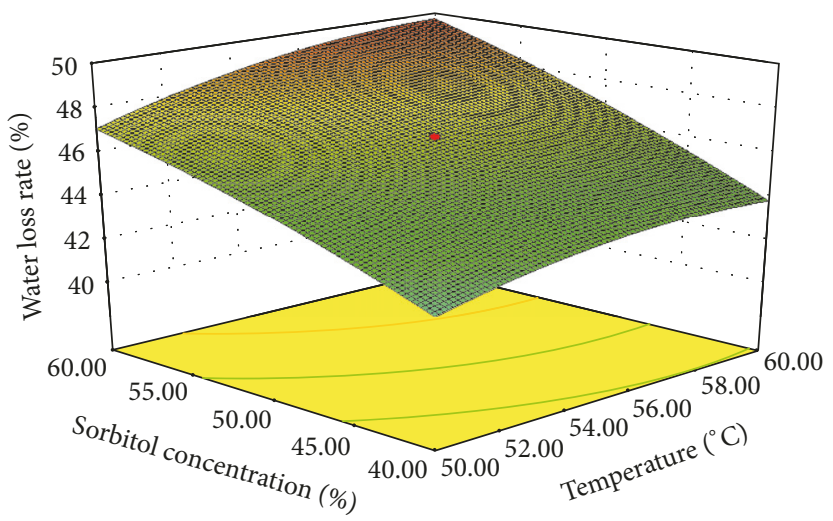

(c)

FIGURE 1: Response surface and contour plots for response of strawberry water loss rate during osmotic dehydration ((a) the interaction between the osmotic temperature and time; (b) the interaction between the osmotic time and sorbitol concentration; and (c) the interaction between the sorbitol concentration and osmotic temperature).

The ANOVA for the lack of fit test indicates that the model could adequately fit the experimental data $(p<0.05)$.

\subsection{Effect of Osmotic Dehydration Variables on WL Rate for} Strawberry Samples. Response surface analysis was applied to the experimental data (Table 2), and ANOVA was conducted to examine the statistical significance of the WL rate regression model (Table 3$)$. Osmotic temperature $(A)$, time $(B)$, and sorbitol concentration $(C)$ significantly affected $(p<0.01)$ the WL rate of the samples at the linear level. The coefficients of linear terms in the regression equation (3) indicated that the WL rate of the samples was mainly influenced by sorbitol concentration ( $p \leq 0.01)$, followed by osmotic temperature $(p \leq 0.01)$ and time $(p \leq 0.01)$. In addition, the interaction of osmotic time and sorbitol concentration $(B C)$ had a highly significant effect $(p<0.01)$ on WL rate within the investigated range, and quadratic term of osmotic time had significant effect $(p<0.01)$.

Figure 1 shows the response surface plot and contour plot of strawberry WL rate under the effects of input parameters of osmotic temperature, time, and sorbitol concentration, considering the interactive effect of variables. Some profiles for the quadratic response surface plot in the optimization of the two parameters were obtained by keeping the other parameter at zero levels for WL rate in order to visualize the interaction effect of the two factors on the response. As shown in Figure 1(a), the WL rate first gradually increases with increasing osmotic temperature and time and subsequently approaches a maximum point. It is consistent with the reports by Lombard et al. [27], where water loss and solids gain increased with temperature and solute concentration during osmotic dehydration of pineapple pieces. This trend may be rationalized by considering that the swelling of cell membrane and plasticizing effect enhance the permeability of the membrane, and thus the intracellular free water movement speed in strawberry accelerates with increasing osmotic temperature [3]. The WL rate will gradually decrease with decreasing amount of free water. When the osmotic pressure between the solution and the internal strawberry cells reaches the equilibrium, the WL rate of strawberry will not change. Figures 1(b) and 1(c) demonstrate the similar trends that the WL rate first increases and subsequently maintains a steady state under the interaction between two parameters.

\subsection{Determination and Experimental Validation of Optimal} Conditions. Process parameters can be optimized by finding the stationary point of the model equation in the ranges of 
TABLE 4: Optimal conditions and validation for strawberry osmotic dehydration.

\begin{tabular}{lccccc}
\hline Temperature $\left({ }^{\circ} \mathrm{C}\right)$ & Time $(\mathrm{min})$ & $\begin{array}{c}\text { Sorbitol concentration } \\
(\%)\end{array}$ & $\begin{array}{c}\text { Predicted water loss rate } \\
(\%)\end{array}$ & $\begin{array}{c}\text { Experimental water loss rate } \\
(\%)^{*}\end{array}$ & $\begin{array}{c}\text { Difference } \\
(\%)\end{array}$ \\
\hline 59.5 & 245.6 & 66.8 & 52.50 & 50.25 & 4.28 \\
\hline
\end{tabular}

${ }^{*}$ Experimental water loss rate was expressed by average value in triplicate for eliminating the experimental errors.

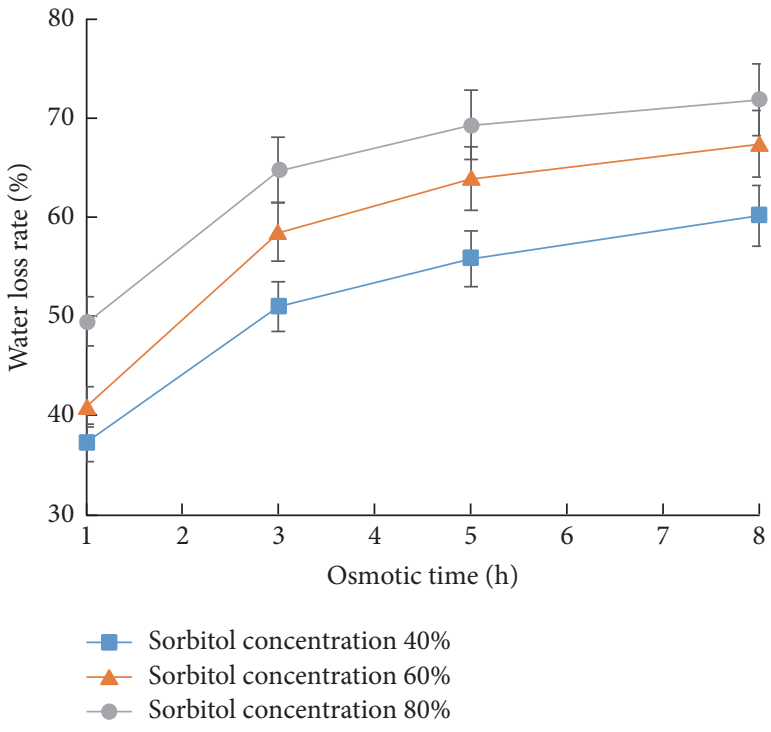

(a)

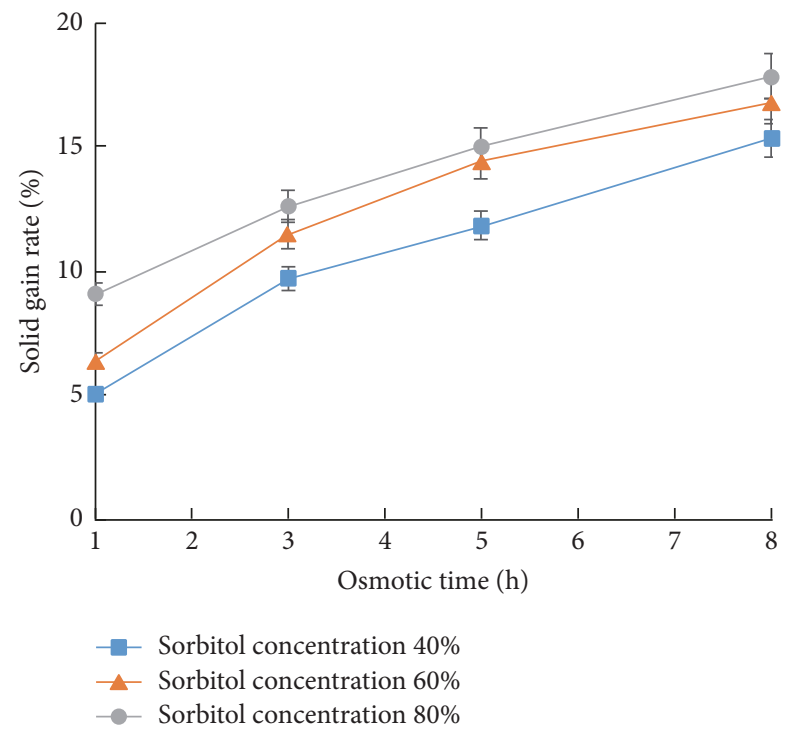

(b)

FIGURE 2: Changes in WL and SG rates for strawberry osmotic dehydration at $60^{\circ} \mathrm{C}$ in different sorbitol concentrations.

tested independent parameters [24]. The optimal conditions were determined by maximizing the desirability of the WL rate. The optimal conditions included osmotic dehydration temperature of $59.5^{\circ} \mathrm{C}$, time of $245.6 \mathrm{~min}$, and sorbitol concentration of $66.8 \%$ with a predicted response value of $52.50 \%$ for WL rate. A confirmation test was conducted using the optimum parameters identified by RSM to verify the adequacy of the regression models. The fitted values predicted by the models were compared with the experimental data. Under these optimal conditions, the experimental value of $\mathrm{WL}$ rate is consistent with the predicted value with $4.28 \%$ difference (Table 4).

3.4. Effect of Sorbitol Concentration on WL and SG Rates. Changes in WL and SG rates for strawberry osmotic dehydration in different sorbitol concentrations at a temperature of $60^{\circ} \mathrm{C}$ were shown in Figure 2. From Figure 2(a), WL rate rapidly increased in the first $5 \mathrm{~h}$ of osmosis, then increasing slowly in $40 \%, 60 \%$, and $80 \%$ sorbitol concentrations. This phenomenon is due to the largest pressure difference between the strawberry cells and the surrounding hypertonic solution, thereby promoting the osmotic dehydration of strawberry in the initial stage of the penetration process and inducing rapid diffusion of the water molecules. As osmotic dehydration time continues, the pressure difference gradually decreases and the structural changes in strawberry tissues gradually occur, the mass transfer approaches the dynamic equilibrium. The WL rate increases with increasing sorbitol concentration, consistent with some other reports. Lenart [28] founded that increasing the concentration of an osmotic solution led to high WL rate until the equilibrium level was achieved; by contrast, low-concentrated sucrose solution led to small WL and $S G$ rates [29].

The strawberry SG rate showed similar trends in $40 \%$, $60 \%$, and $80 \%$ sorbitol concentrations (Figure $2(\mathrm{~b})$ ). The SG rate increased continuously throughout the osmotic dehydration time in the test range, and the increase in the sorbitol concentration could raise the SG rate. High concentration promotes sorbitol mass transfer from the solution to the strawberry cells. The difference in osmotic potential between the solution and the fruit sample resulted in a high diffusion rate of the solute and water $[3,6,30]$. Therefore, the concentration of an osmotic solution affects the mass transfer kinetics during osmotic dehydration [18].

\section{Conclusion}

The optimization of the osmotic dehydration conditions for strawberry was examined using the RSM. The optimal conditions comprised osmotic dehydration temperature of $59.5^{\circ} \mathrm{C}$, time of $245.6 \mathrm{~min}$, and sorbitol concentration at $66.8 \%$ with a response value of $52.5 \%$ for the WL rate. Moreover, the WL rate of the samples was mainly influenced by sorbitol concentration $(p \leq 0.01)$, followed by osmotic temperature $(p \leq 0.01)$ and time $(p \leq 0.01)$. The optimal condition was validated and found to be fitted well with the experimental 
data. Therefore, osmotic dehydration of strawberry highly depends on osmotic temperature, time, and solute concentration. The predicted model for WL rate established by the response surface quadratic regression provided an adequate mathematical description of strawberry osmotic dehydration based on the parameters of ANOVA for the model.

\section{Additional Points}

Practical Application. Osmotic dehydration is accepted as an important method for obtaining minimally processed products. In recent year, demand on intermediate moisture strawberry by using osmotic dehydration has sharply increased in global market. This study aims to optimize processing conditions for osmotic dehydration of strawberry for reducing the dehydration time and producing highquality products.

\section{Conflicts of Interest}

The authors declare that they have no conflicts of interest.

\section{Acknowledgments}

This research was partially supported by Huazhong Agricultural University Scientific and Technological Self-innovation Foundation (2662015BQ019).

\section{References}

[1] B. Yetenayet and R. Hosahalli, "Going beyond conventional osmotic dehydration for quality advantage and energy savings," Ethiopian Journal of Science and Technology, vol. 1, no. 1, pp. 1-15, 2010.

[2] R. V. Tonon, A. F. Baroni, and M. D. Hubinger, "Osmotic dehydration of tomato in ternary solutions: Influence of process variables on mass transfer kinetics and an evaluation of the retention of carotenoids," Journal of Food Engineering, vol. 82, no. 4, pp. 509-517, 2007.

[3] I. Ahmed, I. M. Qazi, and S. Jamal, "Developments in osmotic dehydration technique for the preservation of fruits and vegetables," Innovative Food Science and Emerging Technologies, vol. 34, pp. 29-43, 2016.

[4] M. Riva, S. Campolongo, A. A. Leva, A. Maestrelli, and D. Torreggiani, "Structure-property relationships in osmo-air-dehydrated apricot cubes," Food Research International, vol. 38, no. 5, pp. 533-542, 2005.

[5] P. Pani, A. A. Leva, M. Riva, A. Maestrelli, and D. Torreggiani, "Influence of an osmotic pre-treatment on structure-property relationships of air-dehydrated tomato slices," Journal of Food Engineering, vol. 86, no. 1, pp. 105-112, 2008.

[6] N. Phisut, "Factors affecting mass transfer during osmotic dehydration of fruits," International Food Research Journal, vol. 19, no. 1, pp. 7-18, 2012.

[7] B. A. Souraki, M. Ghavami, and H. Tondro, "Correction of moisture and sucrose effective diffusivities for shrinkage during osmotic dehydration of apple in sucrose solution," Food and Bioproducts Processing, vol. 92, no. 1, pp. 1-8, 2014.

[8] M. Sareban and B. Abbasi Souraki, "Anisotropic diffusion during osmotic dehydration of celery stalks in salt solution," Food and Bioproducts Processing, vol. 98, pp. 161-172, 2016.
[9] J. Shi and J. S. Xue, "Application and development of osmotic dehydration technology in food processing," in Advances in Food Dehydration, C. Ratti, Ed., CRC Press, Boca Raton, Fla, USA, 2009.

[10] G. Moraga, N. Martinez-Navarrete, J. Martine-Monzo, and A. Chiralt, "Influence of convective and osmotic drying on some color and firmness properties of strawberry," in Proceedings of the 12th International Drying Symposium-IDS2000, pp. 1-14, 2000.

[11] C. Osorio, M. S. Franco, and M. P. Castaño, "Colour and flavour changes during osmotic dehydration of fruits," Innovative Food Science and Emerging Technologies, vol. 8, no. 3, pp. 353-359, 2007.

[12] P. M. Azoubell and O. S. Francinaide, "Optimisation of osmotic dehydration of 'Tommy Atkins' mango fruit," International Journal of Food Science and Technology, vol. 43, no. 7, pp. 12761280,2008

[13] N. E. Mavroudis, V. Gekas, and I. Sjöholm, “Osmotic Dehydration of Apples - Effects of Agitation and Raw Material Characteristics," Journal of Food Engineering, vol. 35, no. 2, pp. 191-209, 1998.

[14] M. Dalla Rosa and F. Giroux, "Osmotic treatments (OT) and problems related to the solution management," Journal of Food Engineering, vol. 49, no. 2-3, pp. 223-236, 2001.

[15] S. K. Jain, R. C. Verma, L. K. Murdia, H. K. Jain, and G. P. Sharma, "Optimization of process parameters for osmotic dehydration of papaya cubes," Journal of Food Science and Technol$o g y$, vol. 48, no. 2, pp. 211-217, 2011.

[16] M. A. D. C. Silva, Z. E. D. Silva, V. C. Mariani, and S. Darche, "Mass transfer during the osmotic dehydration of West Indian cherry," LWT - Food Science and Technology, vol. 45, no. 2, pp. 246-252, 2012.

[17] M. Akbarian, B. Ghanbarzadeh, N. Ghasemkhani, F. Mehmandoust, and E. Gheisari, "Optimization of carboxy methyl cellulose-pectin and ascorbic acid based edible coating formulations for performance of osmotic dehydration of quince by RSM," International Journal of Biosciences, vol. 3, pp. 234-247, 2013.

[18] E. Herman-Lara, C. E. Martínez-Sánchez, H. Pacheco-Angulo, R. Carmona-García, H. Ruiz-Espinosa, and I. I. Ruiz-López, "Mass transfer modeling of equilibrium and dynamic periods during osmotic dehydration of radish in $\mathrm{NaCl}$ solutions," Food and Bioproducts Processing, vol. 91, no. 3, pp. 216-224, 2013.

[19] T. Belwal, P. Dhyani, I. D. Bhatt, R. S. Rawal, and V. Pande, "Optimization extraction conditions for improving phenolic content and antioxidant activity in Berberis asiatica fruits using response surface methodology (RSM)," Food Chemistry, vol. 207, pp. 115-124, 2016.

[20] R. H. Myers and D. C. Montgomery, Response Surface Methodology: Process and Product Optimization Using Designed Experiments, John Wiley \& Sons, New York, NY, USA, 1995.

[21] H. S. Ali, H. A. Moharram, M. T. Ramadan, and G. H. Ragab, "Osmotic dehydration of banana rings and tomato halves," Journal of American Science, vol. 6, no. 9, pp. 384-390, 2010.

[22] U. Tylewicz, P. J. Fito, M. Castro-Giráldez, P. Fito, and M. Dalla Rosa, "Analysis of kiwifruit osmodehydration process by systematic approach systems," Journal of Food Engineering, vol. 104, no. 3, pp. 438-444, 2011.

[23] D. Baş and I. H. Boyaci, "Modeling and optimization I: usability of response surface methodology," Journal of Food Engineering, vol. 78, no. 3, pp. 836-845, 2007. 
[24] B. Peng, Y. Lei, H. Zhao, and L. Cui, "Response surface methodology for optimization of fermentation process parameters for improving apple wine quality," Journal of Food Science and Technology, vol. 52, no. 11, pp. 7513-7518, 2015.

[25] B. Singh, A. Kumar, and A. K. Gupta, "Study of mass transfer kinetics and effective diffusivity during osmotic dehydration of carrot cubes," Journal of Food Engineering, vol. 79, no. 2, pp. 471480, 2007.

[26] K. O. Falade, J. C. Igbeka, and F. A. Ayanwuyi, "Kinetics of mass transfer, and colour changes during osmotic dehydration of watermelon," Journal of Food Engineering, vol. 80, no. 3, pp. 979985, 2007.

[27] G. E. Lombard, J. C. Oliveira, P. Fito, and A. Andrés, "Osmotic dehydration of pineapple as a pre-treatment for further drying," Journal of Food Engineering, vol. 85, no. 2, pp. 277-284, 2008.

[28] A. Lenart, "Mathematical modelling of osmotic dehydration of apple and carrot," Polish Journal of Food And Nutrition Sciences, vol. 1, pp. 1-33, 1992.

[29] C. Tortoe, "A review of osmodehydration for food industry," African Journal of Food Science, vol. 4, no. 6, pp. 303-324, 2010.

[30] P. M. Azoubel and F. E. X. Murr, "Mass transfer kinetics of osmotic dehydration of cherry tomato," Journal of Food Engineering, vol. 61, no. 3, pp. 291-295, 2004. 

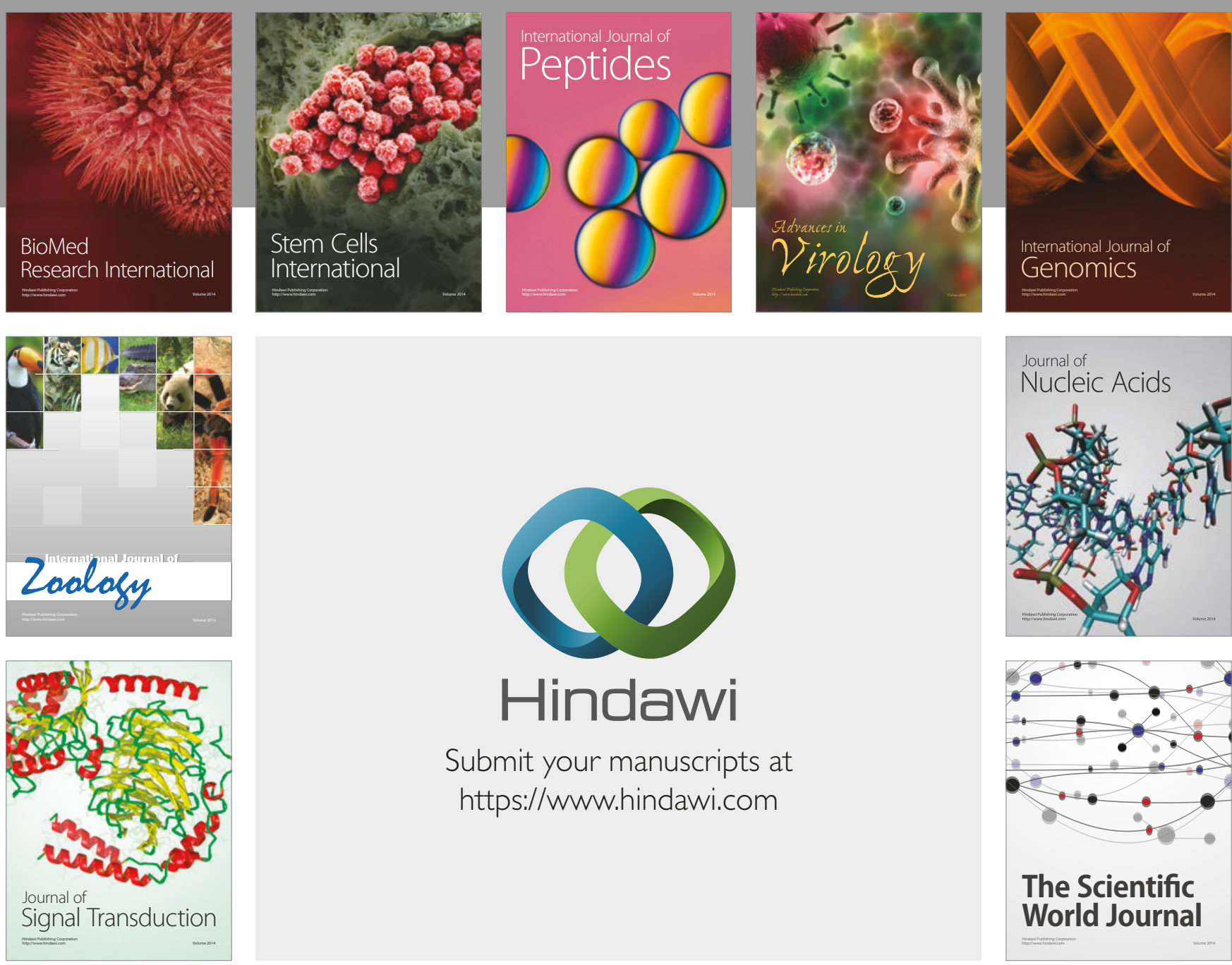

Submit your manuscripts at

https://www.hindawi.com
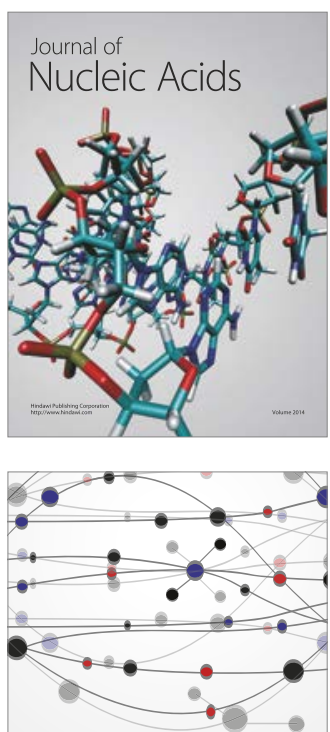

The Scientific World Journal

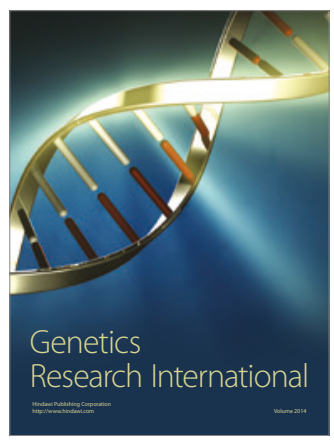

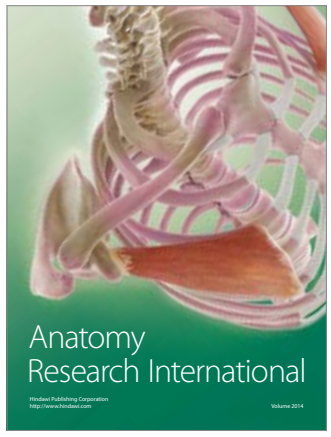

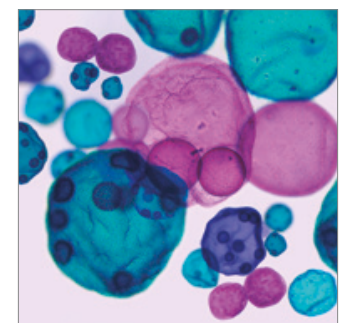

International Journal of Microbiology
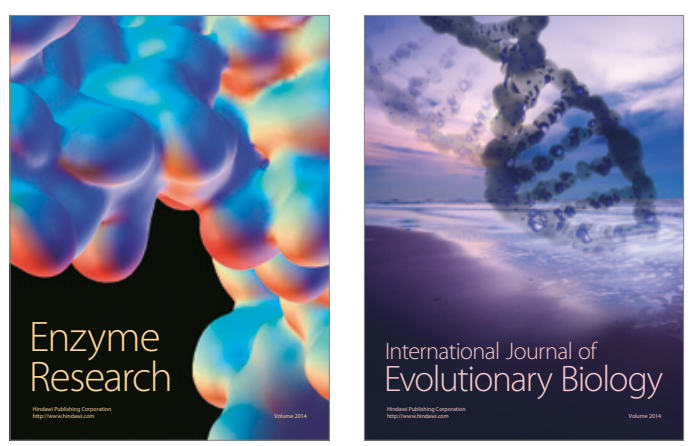
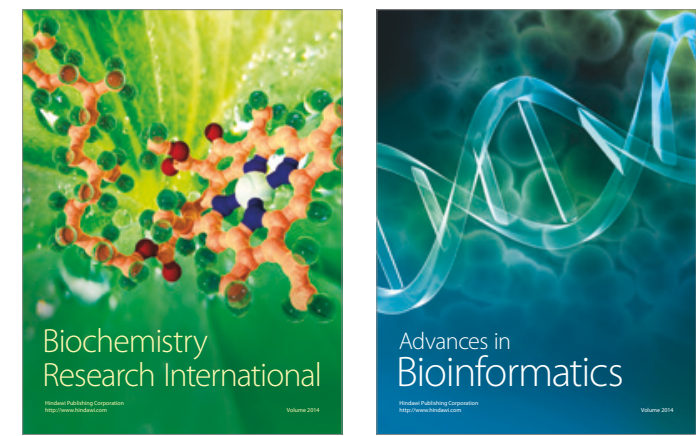

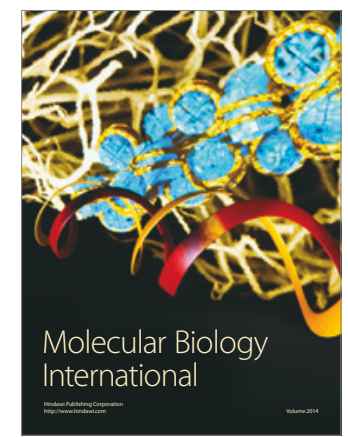

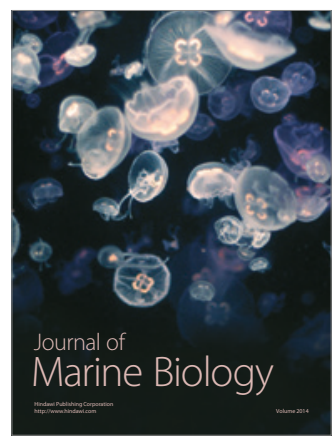

